\title{
Final feliz para um filme natural: Trem da Serra, poema da integração brasileira
}

\author{
Luciana Murari ${ }^{[1]}$
}

\section{Resumo}

Este artigo aborda o livro de poemas modernistas Trem da Serra, publicado por Ernani Fornari em 1928. Seu tema é uma viagem de trem de Porto Alegre a Caxias do Sul, no Rio Grande do Sul, expondo o efeito da imigração na região, e defendendo a miscigenação como forma de incorporação das influências estrangeiras à cultura nacional. São citados textos de autores como Graça Aranha, Monteiro Lobato, João Pinto da Silva e Plínio Salgado para demonstrar a importância do tema no debate sobre a cultura brasileira e a assimilação das influências estrangeiras nos últimos anos da década de 1920.

Palavras-chave: imigração; miscigenação; identidade nacional brasileira;

\section{Final feliz para un documental: Trem da Serra, poema de l'integración brasileña}

\section{Resumen}

Este artículo aborda el libro de poemas modernistas “Trem da Serra”, publicado por Ernani Fornari en 1928. Su tema es un viaje en tren desde Porto Alegre a Caxias do Sul, en Rio Grande do Sul, Brasil, exponiendo el efecto de la inmigración en la región, y defendiendo el mestizaje como una manera de incorporar las influencias extranjeras en la cultura nacional. Se citan intelectuales como Graça Aranha, Monteiro Lobato, João Pinto da Silva y Plinio Salgado para demostrar la importancia de la cuestión en el debate sobre la cultura y la asimilación de las influencias extranjeras en el país en los últimos años de la década de 1920.

Palabras clave: Brasil; inmigración; mestizaje; identidad nacional brasileña.

\section{Happy ending for a documentary: "Trem da Serra", a poem of Brazilian integration}

\begin{abstract}
This paper focuses on modernist poetry book Trem da Serra, published by Ernani Fornari in 1928. The poems deal with a train trip from Porto Alegre to Caxias do Sul, in the state of Rio Grande do Sul, Brazil's extreme south. Their main subject is the effect immigration had on the region, and it defends the notion of miscegenation as the means to incorporate foreign influences. Texts by authors such as Graça Aranha, Monteiro Lobato, João Pinto da Silva and Plínio Salgado are used to demonstrate how seriously that state of affairs was debated in the late 1920's.
\end{abstract}

Keywords: Brazil; immigration; miscegenation; Brazilian national identity;

\section{Une fin heureuse pour un documentaire: "Trem da Serra", poème de l'integration brésilienne}

\section{Résumé}

Cet article trait du livre de poèmes modernistes «Trem da Serra » publié par Ernani Fornari en 1928. Il a pour sujet un voyage en train de Porto Alegre à Caxias do Sul, a l'état de Rio Grande do Sul, au Brésil. Le livre analyse l'effet de l'immigration dans la région, en defendent le métissage comme une façon d'incorporer des influences étrangères à la culture nationale. Cet article fait référence à des intellectuels comme Graça Aranha, Monteiro Lobato, João Pinto da Silva et Plínio Salgado, en fin de démontrer l'importance de ce sujet dans le débat sur la culture brésilienne et l'assimilation des influences étrangères, à la fin des années 1920.

Mots clés : Brésil; imigration; métissage; identité nationale brésilienne. 


\section{Prólogo}

Dentre os temas maiores da vida cultural brasileira a partir das últimas décadas do século XIX estava o incentivo à imigração, relacionado à extinção do regime escravocrata. A questão imigratória, no entanto, transcendia o problema da reposição da mão de obra, uma vez que a atração de trabalhadores de etnias diversas implicava na incorporação de referências culturais alheias ao tradicional universo luso, naquele momento já aclimatado e mesclado às influências indígena e negra. No Rio Grande do Sul, a política de incentivo à imigração teve caráter peculiar, em comparação com o restante do país. Não se tratava de um programa de provimento de mão de obra, pois seu principal objetivo era a colonização do território, através da venda de lotes rurais a famílias dispostas a se instalarem no país no regime de pequena propriedade. Já em 1824 iniciou-se a colonização alemã no estado e, em 1875, principiou a imigração italiana, direcionada à chamada Serra Gaúcha, no noroeste, sendo em seguida expandida a outras regiões (Roche, 1969). ${ }^{2}$

A influência das novas correntes imigratórias, sobretudo alemãs e italianas, na cultura do Rio Grande do Sul, é o tema da coletânea poética Trem da Serra, publicada por Ernani Fornari em 1928. No entanto, o alcance da obra é bem mais amplo. Buscaremos, aqui, inserir esta narrativa lírica de uma viagem da capital, Porto Alegre, a Caxias do Sul, maior núcleo da colonização italiana no estado, no debate de seu tempo, compreendendo a resposta de Fornari às inquietações acerca da construção do futuro num país sedento de transformação, mas cioso quanto à necessidade de valorizar sua tradição cultural e de combater os problemas sociais do campo, em face da influência dos fluxos adventícios recentes. Neste contexto, o problema da imigração estrangeira assume peculiar ressonância, ultrapassando os limites da cultura regional, como veremos a partir de referências a alguns autores fundamentais para a compreensão deste debate em nível nacional: Monteiro Lobato, Graça Aranha e Plínio Salgado.

\section{De todas as querências, uma cidade única}

Máximo símbolo da primeira modernidade industrial - ferro, vapor, técnica, velocidade -, o transporte ferroviário não apenas forjou o encurtamento das distâncias geográficas e a aceleração do ritmo dos intercâmbios materiais, como também promoveu uma grande revolução cultural. As ferrovias limitaram o impacto da distância geográfica sobre as possibilidades de difusão e de permuta simbólica, incentivando a comunicação, a mobilidade, e a ruptura do isolamento entre grupos sociais. $\mathrm{O}$ trem de ferro metaforiza a velocidade das transformações características da experiência moderna, e se define, sobretudo,

\footnotetext{
${ }^{2}$ Na Serra Gaúcha, as principais colônias de origem italiana fundadas foram: Caxias-Nova Palmira (atual Caxias do Sul), Dona Isabel (atual Bento Gonçalves), Conde D’Eu (atual Garibaldi), Nova Trento (atual Flores da Cunha) e Alfredo Chaves (atual Veranópolis). Na região instalaram-se também colônias de povoação mista, como as de Nova Petrópolis, que recebeu imigrantes alemães, boêmios e italianos, e Gramado, de origem açoriana, que recebeu, no início do século XX, alemães e italianos. Ver: De Boni; Costa (1979).
} 
como um signo da integração cultural e da ruptura das fronteiras e das identidades locais. Trem da Serra reflete sobre estes temas, ao criar um meio conceitual de conexão com o diverso, a partir do traçado de uma trajetória que articula simbolicamente o espaço singular da imigração italiana na região serrana do Rio Grande do Sul aos temas maiores da cultura do país.

O livro de Fornari inicia-se por uma metáfora visual arcaizante que assimila o trem de ferro a um cavalo: o flete puro-aço, faminto de distância, digere dormentes e, conduzindo-se entre paralelas que semelham a rédeas, estende suas crinas de fumaça, lançando ao ar uma batida ritmada que remete ao som dos cascos do cavalo.

A "Mallet" ${ }^{3}$ é um flete puro-aço

esfaimado de distância,

com um olho na testa e a dentuça de fora,

puxado pelas rédeas compridas das paralelas.

Ele vai, digere que digere feixes de dormentes,

bufando

e sacudindo ao vento

as crinas trançadas de fumaça ...

Troc-troc... troc-troc... troc-troc...

Isto? É o batido dos cascos do animal!

E aquelas brasinhas que vão ficando pelo chão, o que serão?... (Fornari, 1928) ${ }^{4}$

O poema finaliza, portanto, com um impasse, pois, subitamente, não se encontram mais correspondências entre o trem e o cavalo, subitamente irredutíveis um ao outro, na brusca ruptura entre o antigo e o moderno que interrompe a analogia. O percurso do viajante pela ferrovia será, de fato, marcado pela observação de temporalidades que se cruzam, entre a velocidade do trem e a lentidão do ritmo de vida das comunidades rurais, entre a sucessão cinematográfica de imagens criada pelo movimento e a observação passiva daqueles que se mantêm literalmente à margem da dinâmica contemporânea. Trata-se, sem dúvida, de uma condição privilegiada para a percepção dos desníveis sociais que se sucedem visivelmente, e que fazem o poeta confrontar as diferentes realidades que se sobrepõem no percurso da ferrovia, observadas a partir desta consciência da quebra de continuidade representada pela presença festiva e perturbadora do trem de ferro.

Estes desníveis são novamente observados em "Segunda Parte":

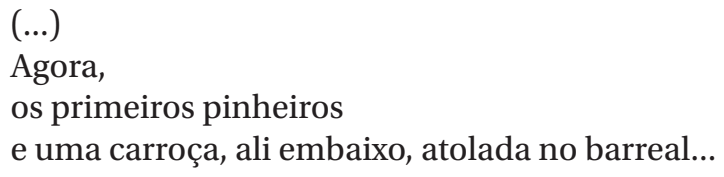

${ }^{3}$ Locomotiva, designada pela marca do fabricante.

${ }^{4} \mathrm{O}$ livro não é paginado e este poema, que é o primeiro da obra, não possui título. No entanto, nos demais casos, serão feitas referências aos títulos dos poemas. Todas as citações diretas foram atualizadas de acordo com a norma ortográfica em vigor. 
Agora,

uma choupana triste, sem horta, sem chiqueiro,

com paredes de taquara e barro formando barriga:

- casa cai-não-cai de índio verminado...

Agora,

um chalé muito claro, muito fresco,

com telhado novo, num cenário de fartura;

- lar de colono que compreendeu toda a bondade do chão que

a gente pisa sem carinho...

Agora,

uma tapera - esperança que falhou... (Fornari, 1928)

Opondo dramaticamente a diversidade de situações que conviviam no interior do mesmo espaço geográfico, exibe-se a contradição entre as miseráveis condições de vida do elemento autóctone e a prosperidade do imigrante, atribuída a uma capacidade de valorização da terra ausente no brasileiro. Na linguagem do poema, a observação da paisagem misérrima do meio rural do país evoca o sentimento de que o filme natural - ou seja, o documentário - que se apresentava aos olhos do poeta-espectador era uma história que, ao contrário dos preferíveis filmes norte-americanos, tinha um triste epílogo ("Desfecho", Fornari, 1928). A melancolia do olhar do poeta frente à desafortunada realidade social do interior brasileiro traduz-se como a falência de um projeto, remetida à imagética da tapera ${ }^{5}$, metáfora de impressionante recorrência na literatura rural brasileira da época como representação da derrota de um ideal de ocupação produtiva do espaço social associado à história da colonização portuguesa no Brasil.

\section{A melancolia do olhar do poeta frente à desafortunada realidade social do interior brasileiro traduz-se como a falência de um projeto}

Esta é, de fato, uma percepção comum no horizonte intelectual brasileiro desde as últimas décadas do século XIX, momento em que grandes transformações sociais que caracterizavam um processo de modernização - sobretudo a abolição da escravatura, mas também o advento da República e a imigração estrangeira - eram assimiladas como decisivas rupturas históricas pelas novas gerações de letrados, formadas sob o influxo das correntes filosóficas de corte científico, materialista e progressista. Este dramático sentimento de quebra da continuidade entre passado e futuro, então onipresente na produção intelectual brasileira, permite compreender que ao olhar para um morro recém-preparado para o plantio junto à região colonial, o poeta veja nele "um enorme crânio encarapinhado/ De tio-mina até as orelhas enterrado", nova metáfora arcaizante que evidencia a sobreposição imaginária da imigração europeia à história do trabalho escravo, à qual ainda se associavam os esforços de utilização produtiva da terra.

${ }^{5} \mathrm{O}$ termo tapera, originado da língua tupi, refere-se a uma aldeia indígena abandonada, ou a uma casa em ruínas. 


\title{
(...)
}

\author{
Aboletado no banco vascolejante \\ do meu cinema ambulante, \\ fico olhando para a "tela" Pathé-Baby da vidraça, \\ onde a paisagem dispara, assustada, para trás. \\ Os postes telefônicos se sucedem, \\ junto dos trilhos, \\ formando uma paliçada interminável... \\ É aqui que a terra-zebu principia aos tombos \\ a fazer calombos. \\ Na distância andam homens depilando \\ a giba dromedária de uma montanha peluda.. \\ Olha, \\ Aquele morro recém-queimado que se vê ali, \\ não parece um enorme crânio encarapinhado \\ de tio-mina até as orelhas enterrado? \\ Olha \\ aquele ventrudo monte chico-boia ${ }^{7}$, \\ muito lá, \\ caminhando devagar \\ no "RETARDADOR"8 esfumado da distância... ("Cinematógrafo", \\ Fornari, 1928)
}

De fato, a sucessão de imagens deste poema, em que a janela do trem reproduz com exatidão a perspectiva do espectador, remete à modernidade do cinema, modernidade também traduzida pelas referências à telefonia e ao boi zebu. ${ }^{9}$ A sucessão das cenas cria associações imagéticas em que o passado colonial e o presente marcado pelas transformações produtivas e tecnológicas compõem um roteiro que encena poeticamente a história brasileira recente. $\mathrm{O}$ drama da população nativa será retomado no poema "Pobre nativo!", em que o escritor enfatiza a drástica oposição entre o aspecto doentio do brasileiro e a exuberante saúde das robustas e coradas famílias italianas. Em contraste com "aqueles risos de saúde", observa-se, novamente, "a casa cai-não-cai do índio verminado", o que leva o poeta às lágrimas - e que sugere que o referencial adotado pelo escritor é, de fato, o povo brasileiro, naquele momento representado pelo esquecido homem pobre do meio rural.

$$
\begin{aligned}
& \text { (...) } \\
& \text { Um italiano cor-de-rosa, }
\end{aligned}
$$

\footnotetext{
${ }^{6}$ Projetor de cinema lançado na década de 1920, de origem francesa.

${ }^{7}$ Referência ao comediante norte-americano Fatty Arbuckle.

${ }^{8}$ Aparelho que eleva o número de imagens em um filme na projeção em velocidade normal, permitindo a análise dos movimentos.

${ }_{9}^{9}$ Apesar da resistência dos produtores tradicionais, o boi zebu, originado da Índia e do Oriente Próximo, passou a ser incorporado à economia pastoril do Rio Grande do Sul a partir das últimas décadas do século XIX, para melhoramento dos tipos crioulos, tornando-se sinônimo de modernização.
} 
Sentado num banco a meu lado, (ele, mulher e oito robustos ítalos, quase todos tenores e sopranos) abriu um enorme embrulho feito com um Diário de Noticias.

Em seus olhos contentes leio uma frase feita:

"A economia é a base ... etc"

O menor está chorando:

também quer um pedaço de presunto...

- Taze ti, sacramigna! ${ }^{10}$

Parece que as maças do rosto dessa gente vão arrebentar, de tão graúdas e maduras que elas estão...

E a gurizada ri, ri cristalinamente, risadas frescas de água nascente caindo no vale, porque o pai tingiu os bigodes de roxo no vinho sem pau campeche...

Àqueles risos de saúde, fecho os olhos para ver, lá atrás, lá longe, onde o trem a deixou esquecida, A casa cai-não-cai do índio verminado...

Quando os abro, tenho-os rasos da água... ("Pobre Nativo!", Fornari, 1928)

O imigrante é, por outro lado, o elemento que franqueia ao escritor um olhar utópico. A partir da imagem de "um casal de lavradores colonos enlaçados acenando para o trem", o escritor define o máximo contentamento, miragem verdadeiramente paradisíaca: "Que ingenuidade naquelas gestos simples!/ Quanta bondade sem interesse/ Naquele "boa viagem" que eles dizem com as mãos!.../Pureza ... Tranquilidade ... Saúde ... Solidão.../ Achei-a! achei-a ! ei-la - a Felicidade!" Os signos atribuídos à colonização italiana por Ernani Fornari são, de fato, todos positivos, em contraste com a consternação despertada pelo caboclo brasileiro - doentio, miserável, apático. Esta dualidade dramatiza a heterogeneidade do espaço social observado no percurso, e encaminha o poema para a busca de uma possível conciliação entre estes dois extremos que se poderiam conceber como componentes de realidades simultâneas, mas completamente dissociadas.

As questões aí apontadas pelo autor estão claramente associadas a uma problemática que permeava o debate intelectual brasileiro já há alguns anos, tendo como referência a obra de Monteiro Lobato. O escritor paulista estreou bombasticamente na literatura nacional com Urupês, de 1918, coletânea de contos regionalistas que se encerrava com amargas reflexões, datadas de 1914, sobre a pobreza do interior brasileiro, personalizada pelo emblemático Jeca Tatu, verdadeiro depositário das mazelas nacionais: indolente, destrutivo, rotineiro

${ }^{10}$ Fala dialetal italiana: cale-se. 
e destituído de qualquer estímulo progressista. Neste primeiro momento da obra de Lobato, a condenação do caboclo surge como um absoluto e tem como corolário o que o escritor define como a inferioridade do homem em relação à natureza brasileira, em relação à qual se estabelecia uma relação depredatória. Esta ideia é traduzida por Ernani Fornari como a falta de apreço do brasileiro pela sua terra, em contraste com a gratidão do imigrante, em seu "lar de colono que compreendeu toda a bondade do chão que a gente pisa sem carinho"... ("Segunda Parte", Fornari, 1928)

A precariedade técnica do interior brasileiro, que conduzia ao desperdício de recursos e à destruição do meio físico-natural do país, poderia, portanto, ser enfrentada pela contribuição racionalizante do trabalhador europeu. Lembre-se que a criação da personagem Jeca Tatu foi motivada por uma intenção de denúncia dos métodos destrutivos de uso dos recursos naturais vigentes no interior brasileiro. Lobato citava o imigrante italiano, juntamente com o arado, a via férrea e a valorização da propriedade, como elemento característico do progresso material nas primeiras décadas do século XX, em oposição ao caboclo que, frente à mudança social, "recua para não adaptar-se" (Lobato, 1982, p. 141).

As ideias de Fornari mostram-se ainda mais conectadas à temática lobatiana à medida que a miséria do caboclo ${ }^{11}$ é associada à doença, e não a uma condição constitutiva de seu organismo, em consonância com uma transformação do pensamento de Monteiro Lobato associada à difusão do pensamento médico higienista, a partir de 1918. Lobato converte o problema da miséria rural em questão propriamente política, uma vez que o tom fatalista - associado, de fato, à previa abordagem raciológica, que condenava o caboclo por uma pretensa inferioridade racial - dá lugar a uma campanha de mobilização das classes políticas e da inteligência nacional em prol da cura das populações rurais, nulificadas por moléstias crônicas que responderiam por sua debilidade física e mental (Lobato, 1946). O impacto de suas ideias tornou-se ainda maior à medida que seu discurso foi incorporado, em 1919, por Rui Barbosa, então candidato à presidência da República, o que torna nítida a conotação política assumida pela obra do escritor paulista (Barbosa, 1919).

As assertivas de Lobato assumem, então, um tom claramente combativo e, doravante, esperançoso, pois a questão apontada por ele em tons tragicômicos em Urupês mostra-se, no Problema Vital, passível de solução, desde que reconhecida sua importância como grande causa nacionalista. A partir de 1924, a militância de Lobato é expressa no seu didático e popularíssimo Jeca Tatuzinho, peça publicitária divulgada pelo Almanaque do Biotônico Fontoura, na qual a redenção do Jeca é insistentemente associada à ideia de que, uma vez curado de suas patologias crônicas, o caboclo "além de preguiçoso, bêbado; e além

"O termo "caboclo" é, por vezes, restrito ao mestiço do indígena com o branco, mas seu uso era, e ainda é, bem mais genérico, referindo-se amplamente ao homem pobre do meio rural, sobretudo no centro-sul, seja ele o indígena "puro", o mestiço indígena com brancos ou negros (o cafuso), ou mesmo simplesmente um tipo social, o sertanejo, ou caipira. Na linguagem regional sul-rio-grandense, o "índio" referido por Fornari pode ser definido como sinônimo do "caboclo" de Lobato. 
de bêbado, idiota, (...) ficará forte, rijo e rico como o italiano" (Lobato, 1946, p. 339). O imigrante surge, portanto, como no poema de Fornari, como a medida das possibilidades de saúde, progresso e de prosperidade no meio rural brasileiro, em consonância com um ideal de superação das mazelas coloniais que promoveria a sincronização do país com a modernidade capitalista.

Ao repercutir as inquietações sociais lobatianas, o poeta do Trem da Serra repercute também suas inquietações políticas, especialmente à medida que, na representação literária de sua viagem à colônia italiana, esta debilidade do elemento nacional é posta em contraste com a vitalidade do imigrante, configurando dois polos opostos e contraditórios em sua essência, mas que necessitavam ser conectados para que se impusessem a unidade e a coesão necessárias à construção da identidade nacional. O Trem da Serra passa a se mover, daí em diante, em direção à conciliação entre as duas realidades contrastantes que até então dividiam seu olhar entre a felicidade do imigrante e o melancólico destino do homem brasileiro, para a concretização de um ideal nacionalista que o poema encarregar-se-á de difundir. Se, em grande parte do texto, sua expressão tem viés nitidamente documental e sociológico, mesmo na segunda metade da obra, de tom mais intimista e autobiográfico, a aventura amorosa do poeta remete ao encontro das diferenças culturais, mediadas pela memória de um "amor ítalo-brasileiro": sua "gringuinha", com seus "olhos meridionais" que "o sol da minha terra amorenou", é também um referente de integração afetiva entre o nativo e o imigrante.

O teu amor passou

na minha vida estéril, italianinha,

como o gume de um arado abrindo sulcos pelo chão.

Sofri, ó Milagrosa tozetta ${ }^{12}$ que o sol da minha terra amorenou, mas sofri como a terra, heroico, sem gemer!

É que eu adivinhava que o amor para ser bom, rasga primeiro, para depois fazer florir...

E eu hei de florir, quando cicatrizar!

(Havia naquela dor qualquer coisa de prazer, - prazer maternal do chão virgem que se entrega pela felicidade humilde de dar à luz searas louras e vindimas fartas).

Orgulho-me nas feridas que fizeste, Bendizendo o amor que arroteou a minha vida...

(Meus pensamentos têm, agora, um gosto de sazão, e o meu sangue está cheiroso como a resina dos pinheiros.)

Amo-te, ó italianinha lavradora da Emoção, pela glória que me deste de frutificar, pela graça divina de florir!

${ }^{12}$ Fala dialetal italiana: moça. 
Fecundação!...

(Trago plantado um pomar no cérebro,

e um jardim no coração...)

Sinto que sou todo uma paisagem serrana,

italianinha!... ("Lavradora", Fornari, 1928)

A relação amorosa pode ser aqui lida como uma metáfora da colonização que, na linguagem do poema, fertilizou as áridas terras da encosta da serra. Neste, e em outros momentos, pode-se observar novamente que, apesar de ser, ele próprio, originado de uma família de imigrantes italianos, é a partir da perspectiva do brasileiro que Fornari retrata a paisagem geográfica e humana da serra, e é assim que rememora seu idílio intercultural, capítulo lírico e subjetivo que participa de uma visão ampla das grandes questões nacionais. Compreende-se, portanto, que, frente à dramática dualidade caboclo versus italiano, Ernani Fornari conduza o Trem da Serra em direção à utopia da superação das diferenças em torno de um ideal comum: "Quando nós formos joão-de-barro, havemos de fazer, também, de todas as querências, uma cidade única”, escreve ele. Ressalta-se, entretanto, que esta unidade é, em seu poema, construída a partir da aliança e da síntese das identidades em um todo diversificado e, simultaneamente, equilibrado. A heterogeneidade pode, portanto, ser vista como um ponto de partida alvissareiro, princípio constitutivo da multiplicidade submetida à coesão, no poema "Estação de parada":

Burburinho. Lufa-lufa. "Com licenças" apressados...

Alemães, italianos, rio-grandenses,

fundindo ao sol um idioma novo singular,

com que todos se entendem:

- Oigalê ${ }^{13}$ alemoa tafuleira! ${ }^{14}$

- Varda, Angelin, quella toza li! ${ }^{15}$

- Mein liebchen, wie bist du mager! ${ }^{16}$

Harmonia... Colorido...

Tenho o corpo doído, os membros lassos, os olhos abertos como bocas sequiosas querendo beber todos os aspectos de uma vez... (Fornari, 1928) (...)

A utopia integradora de Fornari torna-se ainda mais clara no poema "A conquista da Serra", narrativa de origem que imagina o nascimento de uma nova era a partir de um casal edênico que representa a fusão dos opostos para a criação de uma etnicidade reabilitada. Aí residiria a possibilidade de redenção da terra brasileira e de incorporação do autóctone, então relegado a uma

\footnotetext{
${ }^{13}$ Fala regional gaúcha: ouça.

${ }^{14}$ Fala regional gaúcha: mulher vistosa, elegante.

${ }^{15}$ Fala dialetal italiana: Veja, anjinho, aquela moça.

${ }^{16} \mathrm{Em}$ alemão: Minha querida, como você está magra!
} 
existência miserável, à trajetória de prosperidade e progresso material até então unicamente associada ao imigrante. Inicialmente temos, como nos poemas anteriores, duas realidades contrastantes, a "china" e o "gringo" 17 . Enquanto "o rancho da china" era de coberto de palha, o gringo, identificado desde o início com a abundância e a vitalidade, constrói uma "casa com telhado de tabuinhas". O italiano assume, neste poema, um papel de fato messiânico, associado ao mar, elemento ativo, enérgico, masculino, capaz de acordar a brasileira de seu "sono milenar". É ele, simultaneamente, o portador das sementes que fertilizam a montanha, e que "milagrou aquele chão que era só pedra". Fertiliza, igualmente, a "china", elemento passivo associado à fixidez da terra e, novamente, ao entorpecimento. Da aliança dos dois nasce o mestiço representativo do novo tempo em que ambos são redimidos. Se para a "china" - ou melhor, para o brasileiro - esta é a possibilidade de superar a letargia da pobreza e da doença, para o "gringo" este é o momento em que se vê "transformada em esperança, a desilusão do seu País..."

$$
\begin{aligned}
& \text { (...) } \\
& \text { O gringo veio do mar ... }
\end{aligned}
$$

A china estava na terra quando o gringo chegou louro e cheio como a guaiaca cheia de onças de um mascate, e fazendo calar os inhambus:

"La donna é mobile"... ${ }^{18}$

Ela não compreendia, mas pensava que ele trazia para a Terra Nova, transformada em esperança, a desilusão do seu País...

E a china ficou espiando atrás do pinheiral o gringo que chegava, louro como o Sol - que era o deus dos seus avós.

- Buenas tardes pra vancê!!

- Bona sera ${ }^{20}$ !

Que é que ele disse?

E o gringo construiu uma casa com telhado de tabuinhas ...

(O rancho da china era de santa-fé!)

E o gringo plantou trigo na montanha, - milagrou aquele chão que era só pedra...

\footnotetext{
${ }^{17}$ Diferentemente do sentido assumido na região central do país, em que se refere ao estrangeiro em geral, no Rio Grande do Sul termo gringo diz respeito apenas ao imigrante italiano. Já china é um termo regional que, inicialmente, designava a mulher indígena, mas acabou sendo aplicado não apenas a ela, mas também à mulher mestiça ou mesmo morena, que no centro-sul do Brasil seria provavelmente designada como "cabocla".

${ }^{18}$ Referência à ópera italiana Rigoletto.

${ }^{19}$ Fala regional gaúcha: boa tarde para você

${ }^{20}[$ sic] Do italiano: boa tarde.
} 
E a china ficou espiando aquele estranho que plantava

também cabelos louros no cocuruto da montanha.

E gostou tanto da maciez estranha da seara

que quis deitar-se sobre ela e adormecer...

(Até parecia os cabelos dele!)

- Per bacco! ${ }^{21}$

Mas, o italiano que era esperto despertou a china linda que dormia

aquele sono milenar ...

Houve um estremecimento mais violento no trigal...

- Psiu! Cala o bico, bem-te-vi! Faz que não viu!

- Dandá, dandá

Pra ganhá tem-tem!22

- Figlio mio!²3 ("Conquista da Serra”, Fornari, 1928)

Este foi um tema recorrente da literatura nativista dos povos americanos desde o Romantismo, sendo o Novo Mundo definido como o lócus da renovação da cultura ocidental a partir de uma nova relação com a natureza, frente à decadência e ao artificialismo da civilização europeia, tema vigorosamente reeditado nos anos que se seguiram à deflagração da Grande Guerra. Na versão de Fornari, o Brasil, terra prometida, pode, a partir daí, oferecer suas benesses igualmente aos imigrantes e aos nativos, sendo reservada aos europeus uma missão fundamental para os destinos do país, a dinamização da vida brasileira e sua inserção no ritmo internacional de progresso técnico e de melhoria das condições materiais de vida, missão que não poderia ser cumprida, entretanto, sem sua integração à população local. Caso contrário, a polaridade caboclo versus italiano, dramaticamente representada nos poemas anteriores, estaria mantida.

\section{Já não seremos nós}

As questões apontadas por Fornari correspondem, assim, ao debate nacionalista que ocupava as mentes dos intelectuais naquele final dos anos 1920. A discussão sobre o impacto da imigração europeia sobre a formação da nacionalidade era, no entanto, bem mais antiga, tendo se apresentado à intelectualidade brasileira através de Canaã, lançado em 1902 e logo convertido em impactante sucesso editorial. Entre a ficção e o debate de ideias, o romance de 
Graça Aranha encena os conflitos da modernização brasileira a partir da introdução da mão de obra imigrante, teatralizando os impasses acerca de sua ação potencialmente destrutiva em face da tradição brasileira. Graça Aranha concebe o espaço geográfico de Porto do Cachoeiro, povoação onde se desenrola a narrativa, a partir de uma dualidade, pensando a zona colonial - no caso do romance, alemã - como "o limite de dois mundos que se tocavam" (Aranha, 1959, p. 28). De um lado estava o passado, visível nos vestígios decadentes da colonização portuguesa, nos espaços arruinados, nos homens enfraquecidos, prostrados frente à lenta dissolução de seu universo de referência; de outro, a terra nova e já próspera dos imigrantes, onde haveria de ser construído um novo futuro. Na visão do protagonista Milkau, o ingresso dos europeus representava o fim de uma tradição nacional a ser inevitavelmente minada pela força do elemento estrangeiro. Ainda que o esterilizante passado colonial, escravocrata e latifundiário, fosse recusado por sua incapacidade de dialogar com o capitalismo avançado, seu abandono representaria uma evidente perda cultural que anularia a possibilidade de comunicação do legado cultural dos antigos aos novos: "o futuro não entenderá o passado" (Aranha, 1959, p. 37).

\section{O Trem da Serra passa a se mover, daí em diante, em direção à conciliação entre as duas realidades contrastantes}

Decerto, a imigração é vista como uma quebra da continuidade histórica, e possui um significado dissolvente à medida que a etnia brasileira, débil em sua incapacidade de absorver plenamente a experiência moderna, é definida como incapaz de resistir à expansão europeia. A zona colonial é, entretanto, na visão do utópico protagonista de Canaã, também definida como o espaço onde haveriam de se fundir as duas raças que então concorriam pelo domínio daquela terra, utopia da síntese criativa que representava a oportunidade de integração da obsoleta tradição brasileira à modernidade: "ali havia de germinar o futuro povo que cobriria um dia todo o solo". Sobretudo, a fusão destes dois mundos até então contraditórios apresentava-se como a possibilidade de renovação através do estabelecimento de um novo padrão civilizacional, o que representava, na linguagem da época, a criação de uma "nova raça". Nativos e egressos conviveriam na dualidade "até se confundirem num mesmo grande e fecundante amor".

Como observou José Paulo Paes em seu estudo sobre Canaã, a imigração apontava para o problema central da modernização brasileira, sobretudo à medida que contraposta à herança fanada da colonização lusa, visível no cenário do pós-Abolição. Se, por um lado, o legado português possuía, segundo Graça Aranha, um aspecto anacrônico e estático que apontava para sua inevitável superação, por outro lado havia também a necessidade de sua integração com as novas matrizes étnicas destinadas a compor o povo brasileiro 
do futuro. Na obra de Graça Aranha, estas duas posições divergentes ganham expressão no célebre debate entre dois imigrantes: o nietzschiano Lentz, que defende a imposição da cultura adventícia, tida como superior, à moribunda raiz lusitana, e o tolstoiano Milkau, entusiasta da fusão amorosa das diferenças.

No discurso deste último, otimista e conciliador, a tradição luso-brasileira deveria ser conservada no espírito brasileiro em comunhão com os demais aportes culturais, reconhecida a ação potencialmente destrutiva das culturas adventícias sobre as formações nativas. Somente assim seria possível restabelecer a continuidade entre o passado, o presente e o futuro do país. A visão utópica de Milkau aponta, assim, para uma aliança pluriétnica capaz de superar a brutalidade da "invasão" estrangeira e a negatividade do passado colonial, por meio da assimilação da tradição à modernidade (Paes, 1992).

Não é difícil, portanto, associar a problemática de Canaã ao ideal integrador do poema de Ernani Fornari, especialmente porque, em que pese seu reconhecimento da falência do modelo português de colonização, visível no aspecto doentio, dissoluto e arruinado dos espaços tradicionais, não há no Trem da Serra qualquer negação do lugar do nativo no futuro do país. Também não é este o espírito do romance de Graça Aranha. Ao mesmo tempo, é atribuído à imigração um papel fundamental na incorporação das populações rurais pobres à dinâmica da vida nacional, e ambos os autores vislumbram no colono europeu a vanguarda da modernização do país.

Fornari defende, assim, a importância da assimilação do passado brasileiro, expressa na valorização do colorido, ou seja, da diversidade cultural, e da harmonia, com a promoção de um equilíbrio dos elementos até então contraditórios. Neste momento, o poeta respondia a um debate cultural estabelecido, sobretudo, a partir das reflexões de Sílvio Romero, crítico literário responsável pela consagração da miscigenação como verdadeiro traço distintivo da nacionalidade brasileira. Para se ter ideia da apreensão que o influxo das correntes imigratórias despertava entre os intelectuais nacionalistas, ressalte-se que o próprio Romero, autor da "teoria do branqueamento", ${ }^{24}$ sobressaltava-se com os elevados graus de autonomia das comunidades rurais de imigrantes no Rio Grande do Sul. Ele postulava, por isso, a adoção de medidas para que as populações adventícias fossem assimiladas à dinâmica brasileira. De fato, não apenas isto era tido como necessário ao próprio processo do "branqueamento", como também representava a defesa de uma tradição cultural de origem portuguesa que, na visão do crítico, definia a especificidade do ser nacional. ${ }^{25}$

\footnotetext{
${ }^{24}$ Em sua História da Literatura Brasileira, publicada originalmente em 1888, Romero defendia que, com o extermínio das populações nativas através da guerra e da miscigenação, com o fim da escravização dos negros e com a continuidade da política de incentivo à imigração europeia, os traços físicos resultantes da presença das chamadas "raças inferiores" na formação do brasileiro seriam eliminados. O tipo nacional seria o "branco presumido", de aparência europeia, mas fortalecido em sua capacidade de sobrevivência nos trópicos pela influência da ascendência negra e indígena. Ver: Romero (, p. 98-121).

${ }^{25}$ Esta preocupação é mais acentuada no que diz respeito ao imigrante alemão, visto como mais distanciado das raízes culturais brasileiras que o italiano. Encontramos esta ideia, por exemplo, em Romero (). Sobre o tema, ver Schneider (2005, p. 155-189).
} 
No caso de Graça Aranha, esta visão é mais clara em sua obra A estética da vida, publicada em 1921. A despeito da recepção bastante positiva do romance de 1902, com seus questionamentos sociológicos e filosóficos relacionados à substituição da mão de obra escrava pela imigrante, o autor praticamente abandona a temática da imigração nesta segunda obra, enfatizando a influência das três "raças fundadoras" - portugueses, indígenas e negros - na formação da identidade brasileira. Extremando a preocupação que a influência do imigrante já havia despertado em Canaã, a curta manifestação do autor acerca do problema imigratório n'A estética da vida exemplifica a radicalização do debate nos anos 1920. Vendo no Brasil de seu tempo a continuidade do desenvolvimento do espírito expansionista da alma portuguesa, direcionada para a conquista e o povoamento de novas terras, Graça Aranha defende a unidade moral entre a antiga colônia e sua metrópole, o velho espírito luso atualizado pela natureza americana (Aranha, 1920, p. 137-147).

Também concebendo a mestiçagem como a mais perfeita tradução do espírito brasileiro, o autor define o povo brasileiro de seu tempo como a resultante do equilíbrio entre as três grandes etnias formadoras, prevendo um inevitável conflito entre este mestiço brasileiro e o imigrante europeu. A única saída para o conflito seria, afirma ele, a absorção deste último pelo primeiro, a "sentinela da nação". A continuidade da miscigenação restabeleceria a estabilidade do tipo nacional, com a necessária precedência do elemento português. Sua receita para o sucesso é a proteção contra a "ameaça" estrangeira, através do fortalecimento da atitude nacionalista:
Reforcemos o quadro da nação. Não permitamos que dentro dele reine a alma de outros povos e a nossa própria alma seja expulsa e, exilada da terra que lhe criou a expressão ainda incerta, mas ardente e luminosa. Enquanto não tivermos, sólidas, as fronteiras morais da nação, enquanto o quadro que encerra a pátria não for rijo e inquebrantável, fechemos a porta à invasão, defendamos a frágil muralha, solidifiquemos a argamassa, e seja tudo impe- netrável ao sentimento estrangeiro. A pior invasão é a que infil- tra no sentimento, a que transforma a alma, transmuda a poesia secreta da sensibilidade, dá outro ritmo ao sonho, transfigura o pensamento (Aranha, 1920, p. 179-180).

Na visão de Graça Aranha, ainda que a influência estrangeira fosse positiva do ponto de vista do fortalecimento da economia nacional e da atualização do país em relação às conquistas da civilização europeia, permitindo a conquista da riqueza e da prosperidade proporcionadas pela modernidade tecnológica, nada disto valeria a pena se perdido o nexo com a tradição lusa, pois "já não seremos nós". Ele repete, então, a sentença ameaçadora que já havia escrito em Canaã: “O futuro não entenderá mais o passado..." (Aranha, 1959, p. 180). Observamos, portanto, a gravidade das questões que subjazem ao texto de Fornari, assim como sua abordagem conciliadora e desassombrada em relação à questão imigratória, simultaneamente dotada de espírito crítico e de uma mirada sonhadora que 
vislumbra a criação de um equilíbrio, pela via da mestiçagem, entre os referentes contraditórios que até então se sobrepunham no cenário nacional.

Embora se encaminhasse para a defesa da integração da cultura nativa à cultura europeia, como forma de reabilitação da primeira, Fornari não expressa esta visão alarmista de Graça Aranha e Sílvio Romero a respeito da influência do imigrante, segundo eles um elemento destrutivo por sua capacidade de anular a tradição lusa formadora da identidade brasileira. A atualidade dos temas que o poeta então apresentava em seu poema da imigração pode ser também observada a partir da apreciação crítica de seus poemas por Plínio Salgado, ${ }^{26} \mathrm{um}$ dos intelectuais mais atuantes nos debates acerca da criação de uma autêntica cultura brasileira, bastante em voga quando da publicação do Trem da Serra.

A temática da brasilidade tornara-se o centro da reflexão intelectual no país a partir de 1924, quando o movimento modernista paulista superou seu primeiro momento iconoclasta e cosmopolita e deu sua guinada em direção ao nacionalismo. Inspiradas por Graça Aranha, duas correntes destacavam-se, naquele momento: de um lado, os intelectuais do grupo de Oswald de Andrade, de outro os do grupo verdeamarelista de Plínio Salgado. Como observou Eduardo Jardim de Moraes, ambas partiam do princípio de que a conquista do universal só poderia ser realizada a partir da observação do específico, ou seja, do nacional, arraigando a produção de cultura no substrato da brasilidade (Moraes, 1978, p. 73-109).

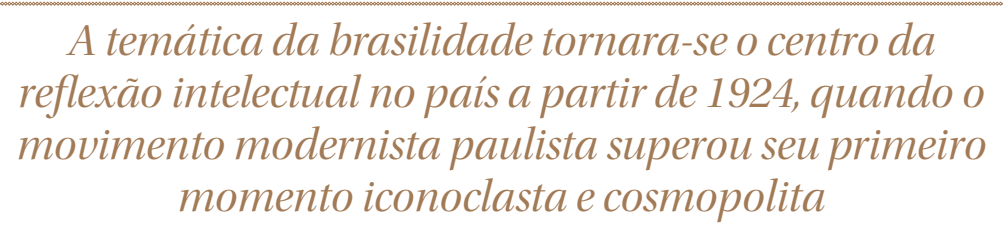

O tema da imigração europeia era, no entanto, incômodo para muitos intelectuais, inclusive aqueles que adotaram as diferentes versões do nacionalismo modernista em voga a partir de 1924. Lúcia Lippi Oliveira observou uma generalizada dificuldade de incorporar a presença do imigrante, sobretudo o italiano, aos projetos culturais que cercavam a "brasilidade". Por um lado, a figura dos imigrantes bem sucedidos que deslocavam as classes tradicionais e constituíam uma nova elite econômica conduzia à crítica do capitalismo através da figura do novo rico, usurpador implacável da riqueza nacional. Por outro lado, a formação de uma classe média trabalhadora que vinha sendo maciçamente incorporada à sociedade brasileira dava vazão aos instintos elitistas característicos das vanguardas culturais. Os imigrantes eram vistos,

${ }^{26}$ Plínio Salgado viria a se tornar célebre, em todo o país, como um dos fundadores e o principal ideólogo da Ação Integralista Brasileira. Fundada em 1932, era um movimento de extrema-direita inspirado no fascismo italiano, e que teve na exaltação nacionalista uma de suas principais bandeiras. 
de qualquer maneira, como potenciais ameaças à autêntica cultura nacional promovida pelos modernistas de diferentes matizes (Oliveira, 2006).

Generalizava-se, entre esses grupos, a percepção de que a essência brasileira só seria alcançada pela via da intuição, capaz de identificar os traços profundos da alma do país pelo recurso à emotividade e à experiência direta. Isto permitiria também reconhecer e rejeitar os elementos falaciosos, alienígenas, infensos à verdade nacional e irredutíveis a ela. Contrária à abordagem científica, analítica, voltada para a descrição pormenorizada e racional dos elementos da cultura brasileira, a proposta do grupo verdeamarelo buscava reconstituir um sentido de unidade, forjando a descrição da alma nacional a partir de grandes traços definitivos de ordem psicológica, com ênfase na coesão dos sentimentos e no enaltecimento da tradição fundadora, capaz de assimilar os elementos alienígenas. ${ }^{27}$ Estes poderiam ser incorporados de bom grado, desde que submetidos à diretriz superior representada pelo patrimônio coletivo da cultura brasileira, seus modos de sentir, suas formas concretas de vivência, seus mitos e lendas, seu passado histórico, sua percepção da natureza - ou seja, sua verdade profunda que transcenderia as manifestações exteriores.

Outra coordenada básica do nacionalismo cultural que então se estabelecia como a linha de frente da produção cultural brasileira era a ideia da integração, ou seja, da incorporação dos opostos através de um esforço de síntese das tendências contraditórias que então conviviam na realidade do país como elementos disparatados e aparentemente inconciliáveis. O símbolo máximo desta proposta unificadora era a dissolução das identidades divergentes, que, na visão verdeamarelista, seriam pacificamente tragadas pela mestiçagem característica da tradição brasileira, incorporadas pelo espírito nacional como agentes modificadores, totalmente destituídos, entretanto, de autonomia. Somente a partir da construção desta cultura da brasilidade, em consonância com o que haveria de genuíno, de espontâneo e de enraizado, seria possível ao espírito brasileiro integrar-se ao universo e passar a interagir de forma autêntica no contexto internacional, absorvendo a modernidade sem se deixar absorver por ela, ou seja, rejeitando aquilo que não poderia ser nacionalizado. Portanto, o cerne desta operação sintética é a mestiçagem, processo de homogeneização via assimilação dos elementos adventícios ao núcleo da brasilidade (Moraes, 1978, p. 163).

O Manifesto do Verdeamarelismo, o Nhengaçu Verde Amarelo, apresenta princípios que se manifestaram em toda a obra doutrinária de Plínio Salgado, para quem a desvalorização dos elementos étnicos que haviam formado o homem brasileiro devia-se ao "esnobismo" derivado da absorção, pelos intelectuais do país, de ideias estranhas à cultura nacional, que segundo ele nunca

\footnotetext{
${ }^{27} \mathrm{Na}$ visão de Moraes, embora tenha sido um dos principais empreendedores do modernismo nacionalista, Mário de Andrade teria adotado um caminho diverso em relação aos grupos de Oswald de Andrade e de Plínio Salgado. Em continuidade com a tradição fundada por Sílvio Romero, Mário de Andrade direcionou-se para a pesquisa das questões nacionais, produzindo uma obra erudita e analítica que acaba por renunciar à criação ficcional em prol da produção do conhecimento. Neste sentido, sua trajetória é divergente, por rejeitar o conteúdo puramente intuitivo, sintético, passional e globalizante dos projetos da Antropofagia e do verdeamarelismo. Ver: Moraes (1978, p. 94).
} 
conheceu o racismo. Pelo contrário, a história brasileira havia sido feita por aqueles que, "antes de desembarcar em Santos, atiraram ao mar, como o cadáver de Zaratustra, os preconceitos e filosofias de origem." (del Picchia; Salgado; Élis; Ricardo; Mota Filho, 1986) ${ }^{28}$ Sua imagem da formação do povo brasileiro repete o "mito das três raças" e investe em uma narrativa não conflituosa da formação nacional.

Então, a meiga ingenuidade do índio, raça infantil em permanente comunhão cósmica, raça constituída de homens-árvores, virginais nas suas impressões e nos seus raciocínios porque vinham agora mesmo da terra, misturavam-se à onda negra vinda das florestas da África no bojo dos navios, para reiniciar o diálogo de Cam com seus irmãos, interrompido na Ásia, depois do Dilúvio. E o branco arremessou de si todos os preconceitos para abraçar seus irmãos (Salgado, 1955, p.126).

Compreende-se, assim, que Plínio Salgado filtre sua avaliação do Trem da Serra, poema que destaca a etnicidade e a assimilação das correntes imigratórias na cultura brasileira, pelos seus próprios ideais verdeamarelistas. Para ele, o país tinha uma unidade política garantida por sua unidade racial, segundo ele resultante da incorporação do índio tupi, ainda vivo nas camadas profundas da personalidade nacional. Ao longo de sua obra, o autor defendeu a ideia de que esta raça não teria desaparecido e, mantendo-se latente no sangue brasileiro, atuava como a força responsável por seu caráter receptivo ao estrangeiro, mas ao mesmo tempo infenso à submissão. "O espírito acolhedor, fraternizador e destruidor dos traços ádvenas veio do mameluco. O índio foi o denominador comum de todas as raças", define Salgado em texto posterior (Salgado, 1978, p. 170). ${ }^{29}$

A mistura racial, de fato, é aspecto privilegiado na obra de Salgado. Aplicado a sua leitura da obra de Ernani Fornari, ele afirma que esta "nos dá a compreender a raça nova", leia-se a "raça" brasileira, síntese capaz de libertar o país de sua característica condição de heterogeneidade. As ideias acima permitem compreender porque, em seu artigo sobre a poesia do Rio Grande do Sul, a imigração estrangeira não representa qualquer ameaça à conservação espírito brasileiro, que se mantinha dominante no "espírito da terra":

Cruzamento de raças, cruzamento de lirismo, de sentimentalismo, de alegria latino-americanas. (...) A conversa sarapintada de idiomas. Caboclos fortes e imigrantes audazes. Vestimentas sarapintadas. Cozinha ítalo-brasileira. Violas, harmônicas, cantigas peninsulares e cantigas brasileiras. E estampas. E pequenos amores obscuros. E o trabalho e a alegria dos campos, dos vales, das montanhas. $\mathrm{O}$ espírito da terra rio-grandense dominando tudo. E, através de tudo, o Brasil palpitando e crescendo. Recebendo o sangue adventício, assimilando, confraternizando. Um Brasil com caráter próprio, que se vai definindo (Salgado, 1930, p. 13-14).

\footnotetext{
${ }^{28} \mathrm{O}$ Manifesto foi publicado no Correio Paulistano em 17 de maio de 1929.

${ }_{29}^{29}$ Para uma introdução à obra de Plínio Salgado, ver Medeiros (1978, p. 379-599).
} 
Percebe-se claramente que o crítico capta a multiculturalidade e a ideologia agregadora da obra de Fornari, ainda que para tal seja obrigado a distorcer as ideias do poeta em prol de suas próprias. Ao contrário do realismo do poeta sul-rio-grandense - que associamos à dramática visão de Monteiro Lobato sobre o homem pobre do interior e à sua militância pela cura das enfermiças populações rurais brasileiras - Plínio Salgado prefere colocar em pé de igualdade os dois grandes tipos humanos em contato, definindo-os como "caboclos fortes e imigrantes audazes", ao contrário de Fornari, que os trata no poema como figuras paradoxais. Não é difícil compreender porque o "índio verminado" de Fornari converte-se no "caboclo forte" de Plínio Salgado, cujo nacionalismo radical recusava a observação realista da miséria rural do interior brasileiro pelo poeta, menos ainda quando seu contraponto era a prosperidade do estrangeiro.

Decerto, o extremado nacionalismo do futuro líder integralista nega-se a colocar o homem brasileiro em posição de inferioridade em relação ao italiano, posição muito diversa da adotada por Fornari. ${ }^{30}$ Como vimos, na visão deste, a precariedade das condições de vida do primeiro legitima a missão salvadora a ser desempenhada pelo segundo, capaz de acordar o nativo de seu "sono milenar". Saliente-se, ainda, na crítica de Plínio Salgado, a ênfase às expressões artísticas diversas e ao componente afetivo e festivo do contato entre os grupos, em direção a uma típica abordagem intuitiva do nacional, obra em processo à medida que formada pela assimilação do estrangeiro a um núcleo nacional de emotividade. O trecho citado acima deixa clara a subordinação desta "contribuição" do elemento adventício às diretrizes fundamentais da brasilidade, ao afirmar o domínio do espírito rio-grandense sobre a realidade peculiar da zona colonial e, superior a este, uma raiz brasileira que se fortalecia ao incorporar a si o estrangeiro, estabelecendo-se como uma cultura autônoma, um "caráter próprio" ainda em formação. O segredo da brasilidade na produção cultural residiria, portanto, no "espírito histórico" e no contato com a "força da terra" pela via da experiência direta:

E é assim que o Rio Grande do Sul cresce e se integra cada vez mais no sentimento brasileiro, que não vem dos livros nem da sabedoria dos leitores da 'Revista do Ocidente' ${ }^{31}$, mas da própria vida vivida em nosso país.

Os 'verdeamarelistas' de São Paulo, que não querem outra coisa, sentem-se profundamente irmanados com essa literatura vitoriosa do Sul, que traz nas suas expressões mais notáveis a força da terra e o espírito histórico da gente do Brasil (Salgado, 1930, p. 14).

A crítica de Plínio Salgado nos diz ao que veio quando absorve o poema de Fornari à plataforma verdeamarelista - às custas, como vimos, de um não

\footnotetext{
${ }^{30}$ Coerentemente, no romance O estrangeiro, de 1926, Plínio Salgado defende a neutralização do nacionalismo fascista italiano em prol da afirmação dos valores da brasilidade. Há, no poema de Ernani Fornari, uma referência discreta à recepção do fascismo pela colônia italiana do Rio Grande do Sul, ao citar o "emblema fascista na lapela" de um imigrante, no poema "Bento Gonçalves" (Fornari, 1928). Segundo Bertonha, havia entre os colonos da zona rural rio-grandense uma simpatia difusa pela doutrina, sobretudo pela influência da Igreja católica, o que, paradoxalmente, ampliou sua futura adesão ao integralismo (2001, p. 218-229).

${ }^{31}$ Revista filosófica fundada no ano de 1923 por José Ortega y Gasset, em Madrid.
} 
muito sutil desvio de significado. Estas observações do autor paulista apontam outro aspecto fundamental para a apreensão do significado cultural do Trem da Serra em seu tempo: a inserção da produção literária rio-grandense no contexto brasileiro, num momento de radicalização das demandas nacionalistas e dos debates modernistas. No caso de Plínio Salgado, afirma-se simultaneamente a integração crescente do Rio Grande do Sul ao Brasil e a brasilidade intrínseca à produção literária do estado naquele momento - elogio enriquecido pela ideia de que, enquanto a literatura paulista pensava mais que criava, os escritores gaúchos eram mais artistas que pensadores. Por isto, segundo ele, o Rio Grande do Sul era o único estado brasileiro possuidor de uma literatura própria, o que, acreditamos, está de certa forma relacionado à revalidação do regionalismo no âmbito do modernismo gaúcho.

O sentido do modernismo no Rio Grande do Sul a partir da influência paulista é assunto de controvérsia. Walter Spalding, por exemplo, ao escrever sobre o Trem da Serra, classifica o poema de Fornari como "verdeamarelismo puro embora afastado, e muito, do movimento verdeamarelista (...)" - ou seja, ao mesmo tempo em que se vê obrigado a reconhecer a convergência entre o texto do autor rio-grandense e as tendências nacionalistas do modernismo, o crítico prefere negar a derivação de um a partir do outro (Spalding, 1967, p. 46). Em sua visão retrospectiva, Spalding toma o verdeamarelismo como sinônimo do nacionalismo modernista e o associa à Semana de Arte Moderna de 1922, buscando conferir ao movimento literário do Rio Grande do Sul, ao contrário, um aspecto autóctone, ou seja, inspirado pelas motivações de sua própria dinâmica cultural, e inclusive por sua tradição regionalista, portanto infenso à iconoclastia dos paulistas e às dimensões propriamente políticas de sua militância cultural. Não há dúvidas, entretanto, acerca da repercussão que os temas discutidos pela intelectualidade paulista adquiriram em Porto Alegre, como também dos intercâmbios constantes entre os jovens intelectuais gaúchos e os modernistas paulistas (Leite, 1972, p. 227-274).

De fato, a literatura de Ernani Fornari mostra-se coerente com a plataforma nacionalista assumida pelo modernismo a partir de 1924, sobretudo no que dizia respeito à criação de uma cultura essencialmente brasileira, capaz de dialogar com a modernidade, mas também de assegurar a continuidade dos caracteres fundamentais de sua formação. Neste contexto, a questão imigratória convertia-se decerto em um ponto nodal do debate de ideias no Rio Grande do Sul, articulando-se tanto às transformações de sua dinâmica interna - sobretudo no sentido do estabelecimento de um campo de força político-econômica oposto aos grupos tradicionais - quanto à sua inserção no contexto brasileiro. Este último aspecto, por sua vez, envolvia a articulação do estado aos debates de âmbito nacional então em curso, como vimos acima.

É expressivo, por exemplo, que, no apêndice de sua História da Literatura do Rio Grande do Sul, o crítico João Pinto da Silva - ao qual, aliás, é dedicado o poema "Domingo lírico", de Trem da Serra - tenha destacado a influência dos elementos ítalo-germânicos na evolução da cultura sul-rio-grandense. Já de início, o autor se preocupa em afastar a possibilidade de que a formação 
étnica do estado viesse a representar algum desequilíbrio social ou alguma incoerência com as linhas gerais da gênese do país, defendendo, ao contrário, sua "tendência para a homogeneidade, com o predomínio das características nacionais, brasileiras" (Silva, 1930, p. 261). Neste processo de integração étnica, o imigrante italiano representaria papel fundamental, por sua capacidade de fundir as raças componentes da população: "Em face dos núcleos estrangeiros de outras origens, ele atua à maneira de poderoso órgão latinizante, o que vale dizer, em última análise, no caso ibero-americano, como agente indireto de nacionalização" (Silva, 1930, p. 261). Para João Pinto da Silva, o imigrante italiano era não apenas um agente fundamental da formação econômica do estado, como também um elemento destinado a desempenhar a missão étnico-sociológica de neutralizar a influência de matrizes raciais capazes de destruir, ou de fragilizar, as "tradições mediterrâneas" características da origem brasileira, colaborando assim, para a manutenção e o fortalecimento da constituição étnica do país. Logo, ao mesmo tempo em que neutralizaria a influência de referentes culturais alheios à essência brasileira - podemos imaginar, sobretudo, germânicos, nipônicos e eslavos -, a imigração italiana congregaria os povos latinos, ampliando sua capacidade de resistência a influências estranhas a esta matriz cultural. Na peculiar concepção de João Pinto da Silva, não é o caráter luso, e sim a latinidade o elemento fundamental a ser preservado face às influências culturais de outros matizes que então tornavam mais complexa a dinâmica social brasileira. Isto possibilitava a ele considerar o italiano um agente, em última instância, fortalecedor da identidade do povo brasileiro.

É sob o ponto de vista étnico-sociológico que ele [o italiano] adquire sua maior significação.

Ninguém ignora que, das quatro nações do Velho Mundo herdeiras diretas do espírito latino, somente Portugal, Espanha e Itália são grandes exportadoras de homens. Das três, porém, é a Itália que nos fornece maior número de trabalhadores rurais. Por isso mesmo é, talvez, a que mais contribui, mediante essas transfusões periódicas de sangue, para evitar que correntes imigratórias de outras procedências interrompam, ou enfraqueçam, entre nós, as tradições mediterrâneas.

Mais do que simples instrumento dinâmico do progresso, é, pois, o italiano, na América Latina, um dos principais fatores de preservação e enrijecimento da nossa personalidade racial (Silva, 1930, p. 261-262).

O texto de João Pinto da Silva demonstra a apreensão despertada pela questão imigratória no Rio Grande do Sul, no tocante à organização social do estado e de sua inserção na nacionalidade brasileira, reafirmando o desejo de integração, de homogeneização, de conciliação das diferenças. Tal como o autor do Trem da Serra, o crítico literário dissolve qualquer argumento que eventualmente indicasse uma influência negativa da imigração sobre a inscrição do estado na nação brasileira. Pelo contrário, ainda que por vias diversas, ambos acabam afirmando a função dinamizadora e unificadora desempenhada pelo imigrante italiano. Ernani Fornari, também participante do grupo de letrados 
reunidos na Livraria do Globo, em Porto Alegre, - aos quais são dedicados muitos dos poemas de Trem da Serra - articulou sua representação da zona colonial aos temas maiores da discussão nacionalista de seu tempo, temas de óbvias conotações políticas como a integração das colônias estrangeiras à sociedade brasileira, a dinamização do sistema produtivo, a representatividade dos grupos sociais não-tradicionais, o amparo estatal às classes pobres e a adoção de uma diretriz modernizante que haveria de incorporar a totalidade da população ao esforço de atualização do país.

\section{Epílogo}

Coerentemente com as questões nacionalistas em debate, Ernani Fornari escreve seu Trem da Serra, poema da região colonial italiana, como um discurso integrador, voltado não tanto para a especificidade de um determinado espaço geográfico, a zona colonial serrana do Rio Grande do Sul, mas para a reflexão acerca dos sentidos da imigração europeia na formação brasileira. Seu foco não é o âmbito local, e nem mesmo o regional, mas a discussão de problemáticas que já haviam se estabelecido, entre a intelectualidade do país, como fundamentais para a definição dos rumos da nacionalidade, no sentido da criação de uma autêntica cultura brasileira. Isto dependia, em primeiro lugar, da concepção de um sentido de identidade capaz de particularizar o país no contexto, internacionalizante por natureza, da modernidade industrial. Não é de se estranhar que os autores aqui referidos como suportes para a compreensão da inserção do poema de Fornari nas contendas intelectuais de seu tempo - Monteiro Lobato e Graça Aranha - tenham sido abordados, pela historiografia, como prenunciadores do nacionalismo modernista (Moraes, 1978; Landers, 1985). De fato, embora ambos tenham sido, em grande parte, rejeitados pelos modernistas, estes autores foram fundamentais para o estabelecimento de uma plataforma que pretendia fazer do problema nacional o fulcro da atuação dos intelectuais, e não apenas no campo da produção artística. Isto, certamente, reflete não apenas uma diretriz literária, mas responde à crescente inquietude da sociedade brasileira, traduzida pelos abalos daquele contexto de emergência de novas forças políticas e de novos projetos sociais, em que o nacionalismo exprimia anseios por maior centralização do poder e por uma decisiva intervenção do Estado na vida social.

A questão do imigrante passava a ser, de fato, uma das mais sensíveis deste contexto, sobretudo à medida que a defesa da brasilidade podia assumir, como diversas vezes assumiu, um viés defensivo - facilmente perceptível, acima, nas falas de Graça Aranha, Plínio Salgado e João Pinto da Silva. O lirismo de Fornari e sua abordagem realista e humanista do contexto social brasileiro são, certamente, uma sensível manifestação de um desejo de harmonia que, naquele momento, frente às disparidades e contradições de um "Brasil profundo" em choque com a modernidade, possuía inegável sabor utópico. De olhos fechados, o poeta imaginava um final feliz para o melancólico "filme natural" assistido a bordo do Trem do Serra. 


\section{Referências bibliográficas}

ARANHA, Graça. A esthetica da vida. Rio de Janeiro: Garnier, 1920.

. Canaã. Rio de Janeiro: Briguiet, 1959.

BARBOSA, Ruy. A questão social e política no Brasil, Revista do Brasil, v. 10, n. 40, p. 381-241, 1919. BERTONHA, João Fábio. O fascismo e os imigrantes italianos no Brasil. Porto Alegre: Edipucrs, 2001. DE BONI, Luís Alberto; COSTA, Rovílio. Os italianos no Rio Grande do Sul. Porto Alegre: Escola Superior de Teologia São Lourenço de Brindes; Caxias do Sul: Universidade de Caxias do Sul, 1979. DEL PICCHIA, Menotti; SALGADO, Plínio; ÉLIS, Alfredo; RICARDO, Cassiano; MOTA FILHO, Candido. Nhengaçu Verde Amarelo. In: TELES, Gilberto Mendonça (org.). Vanguarda europeia e modernismo brasileiro. Petrópolis: Vozes, 1986, p. 361-367.

FORNARI, Ernani. Trem da Serra. Porto Alegre: Editora Globo, 1928.

LANDERS, Vasda Bonafini. De Jeca Tatu a Macunaíma: Monteiro Lobato e o modernismo. Rio de Janeiro: Civilização Brasileira, 1985.

LEITE, Ligia Chiappini Moraes. Modernismo no Rio Grande do Sul, materiais para seu estudo. São Paulo: Instituto de Estudos Brasileiros, 1972.

LOBATO, Monteiro. Problema Vital. In: Mr. Slang e o Brasil e O problema vital. São Paulo: Brasiliense, 1946, p. 221-340. . Urupês. São Paulo: Brasiliense, 1982.

MEDEIROS, Jarbas. Ideologia autoritária no Brasil, 1930-1945. Rio de Janeiro: FGV, 1978. MORAES, Eduardo Jardim de. A brasilidade modernista, sua dimensão filosófica. Rio de Janeiro: Graal, 1978.

OLIVEIRA, Lúcia Lippi. Os italianos, os bandeirantes e os modernistas paulistas. In: Nós e eles: relações culturais entre brasileiros e imigrantes. Rio de Janeiro: FGV, 2006, p. 43-82. PAES, José Paulo. Canaã e o ideário modernista. São Paulo: Edusp, 1992.

ROCHE, Jean. A Colonização Alemã e o Rio Grande do Sul. Porto Alegre: Editora Globo, 1969. ROMERO, Sílvio. História da Literatura Brasileira. Rio de Janeiro: José Olympio, . T. 1.

SALGADO, Plínio. O estrangeiro: crônica da vida paulista. São Paulo: Helios, 1926. . Poetas gaúchos. Revista do Globo (Porto Alegre), 13: 2, p. 13-14, 1930. . A Quarta Humanidade. São Paulo: Editora das Américas, 1955. . O ritmo da história. São Paulo: Voz do Oeste, Instituto Nacional do Livro, 1978.

SCHNEIDER, Alberto Luiz. Sílvio Romero, Hermeneuta do Brasil. São Paulo: Annablume, 2005. SILVA, João Pinto da. Historia literária do Rio Grande do Sul. Porto Alegre: Livraria do Globo, 1930. SPALDING, Walter. Ernani Fornari. [Porto Alegre], 1967. 